\title{
Synthesis and simulation of new cyclodextrin derivatives breaker for $\mathrm{A} ß 42$
}

\begin{abstract}
The amyloid $A \beta-42$, a peptide involved, following a conformational change in $\beta$ sheets in the pathology of the main neurodegenerative disorder of Alzheimer's disease, is targeted in our study, the latter of which reports the synthesis of two Inhibitors linked to a specific recognition sequence synthesized during this work (Tryp-Val-Val-COOH), one linked to an aziridine and the other to a methylated $\beta-\mathrm{CD}$ in order to be able to stop the aggregation of the peptide involved.
\end{abstract}

Keywords: Alzheimer, peptidomimetic, cyclodextrin, fibrillogenesis
Volume 9 Issue 3 - 2020

\author{
Assia Keniche, ${ }^{1,2}$ Katia ouled Taleb ${ }^{2}$ \\ 'Center of Maghnia university, Tlemcen, Algeria \\ ${ }^{2}$ Laboratoire de Chimie Organique, Substances Naturelles et \\ Analyses (COSNA), University of Tlemcen, Algeria
}

Correspondence: Assia Keniche, Maghnia Center University, COSNA laboratory, Tlemcen University Algeria, Algeria, Email Keniche_assia@yahoo.fr

Received: March 02, 2019 | Published: November 30, 2020
Nomenclature: CD, cyclodextrin; Tryp, Tryotophan; Val, Valin

\section{Introduction}

Alzheimer disease (AD) is a neurodegenerative disorder and is associated with accumulation of amyloid and tau depositions in the brain.1-3 If we succeed in blocking fibrillogenesis, we must first block the aggregation of amyloid A $\beta 42$, targeting as far as chemists residues responsible for folding. Several studies have been carried out to identify the minimum sequence necessary for the fibrillation of the $A \beta$ peptide. The $A \beta 19-28$ sequence is sufficient to form amyloid fibers. 4 As for the first 17 residues of the N-terminal part of the $\mathrm{A} \beta$ peptide are not necessary for the formation of amyloid fibers.5 Their elimination makes it possible to amplify the fibrillation. The A $\beta 16-20$ sequence, KLVFF (Figure 1), is designated as necessary for the interaction between $A \beta$ peptides.6,7 Many inhibitors have been developed in recent years, most of which are of peptide nature or are peptide mimics. A large part of the inhibitors is based on the hydrophobic core of the $\beta$ sheet of the N-terminal domain: the LVFF sequence $(\mathrm{A} \beta 17-20) .8-20$

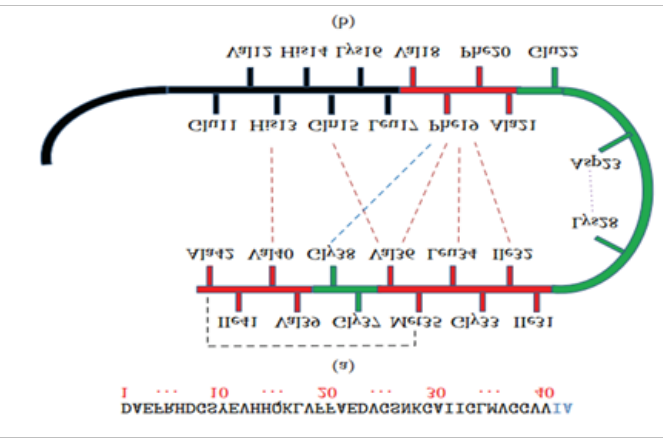

Figure I Structure of $A \beta 40$ and $A \beta 42$ that is involved in fibril formation.2

\section{Materials and methods}

All the reactions with dry solvents were carried out under dry nitrogen. THF was dried over sodium /benzophenone and freshly distilled before use; $\mathrm{CH} 2 \mathrm{Cl} 2$ was distilled and dried over phosphorus pentoxide (P2O5). I.R spectra were collected from a Mattson Genesis
II FTIR. NMR spectra were recorded in $\mathrm{CDCl} 3$ on a Bruker $300 \mathrm{MHz}$ instrument, using tetramethylsilane (TMS) as an internal standard. Chemical shifts are given in $\beta$ (ppm) and coupling constant $(\mathrm{J})$ values in Hertz (Hz). ESI-MS data were recorded in the positive ion mode on a quadrupole instrument (Waters-Micromass ZQ). Melting points were determined on an Electrothermal T1A F3.15A instrument. Column chromatography was performed on silica gel 230-270 mesh (Merck) using $\mathrm{CH} 2 \mathrm{Cl} 2, \mathrm{MeOH}$ and ether. Elemental analysis was performed only for solids on a LECO CHN 900 instrument.

\section{Results and discussion}

\section{Synthesis of $\beta$-Sheet breakers A and B}

Our approch $\square \square$ consist to $\square$ developp $\square \square$-sheet breaker peptides. Several derivatives peptides have been synthesized. The amyloid deposition could be stopped by synthetic peptides partially homologous to the $\mathrm{A} \square \square$ hydrophobic region and containing residues disrupting $\square$-sheet formation (Figure 2). Our synthetic pathways to our target aziridines 6a-e are presented in Schemes 1 and 2. The synthesis of tosylate aziridine 4, was achieved by the O-protection of glycidol 1 with p-toluenesulfonyl chloride ( $\mathrm{TsCl}$ ). And was treated with ammonium chloride and sodium azide to give the azido alcohol 3, which was reacted in the next step with a solution of triphenylphosphine (PPh3). The biological activity of aziridines is highly related to the establishment of covalent bond with DNA.22 In a previous investigation of our group we noted the synthesis of aziridinyl that had antitumor activities against breast cancer cells (Figure 3).23,34

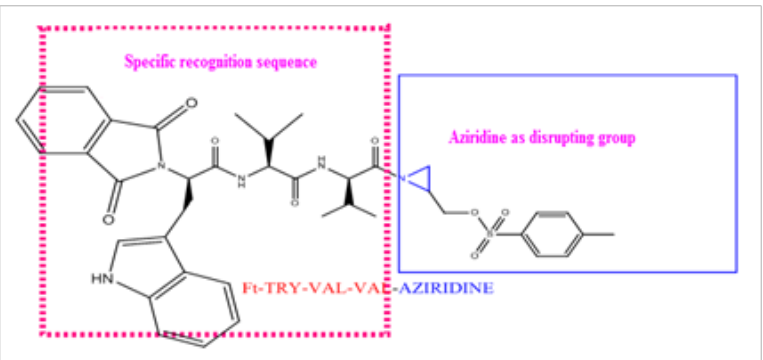

Figure 2 Structure of of $\beta$-sheet breakers $A$ with aziridine moiety as disrupting group. 


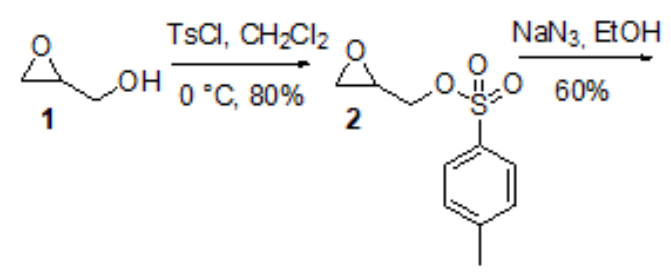<smiles>Cc1ccc(S(=O)(=O)OCC2CN2)cc1</smiles>

Figure 3 Synthesis of aziridin-2ylmethylbenzensulfonate 4.

We have, already reported the synthesis of several aziridines, 25-27 that moiety of amino acids phtaloyl group with a phosphonate, surprisingly, the biological activity of seri of phosphonates aziridines shifted from antiviral to an antibacterial one.28-31 For the second inhibitor, we choose $\beta$-cyclodextrine ( $\square-C D$ ) as disrupting group coupled with the same specific recognition sequence of tripeptid (TryVal-Val) (Figure 4).

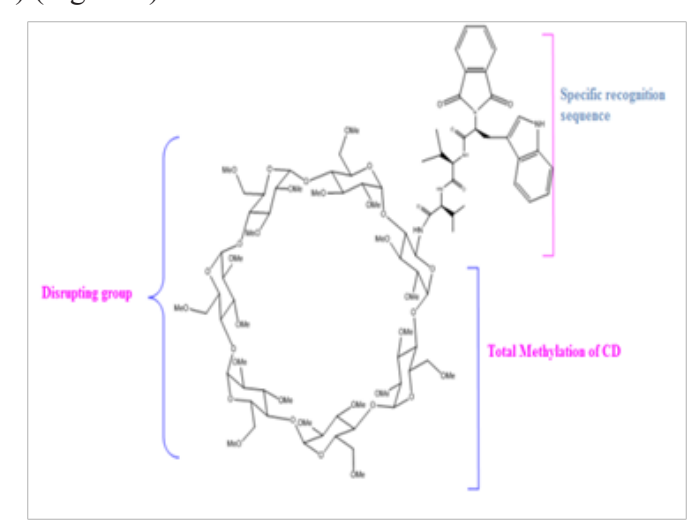

Figure 4 Structure of $\beta$-sheet breakers $B$ with $(\beta-C D)$ mioty as disrupting group.

Cyclodextrins (CDs) are compounds that are produced by the enzymatic degradation of starch. The three most common CDs have 6, 7 , and 8 glucopyranose units in the cyclic and are named $\alpha-C D, \beta-C D$, and $\gamma-\mathrm{CD}$, respectively.32 Whereas the depth of the cavity for these CDs is $\square 8 \AA$, the sizes of the cavity are different for $\alpha-C D, \beta-C D$, and $\gamma$-CD, being $\square 6,8$, and $10 \AA$, respectively (Figure 5).33-44

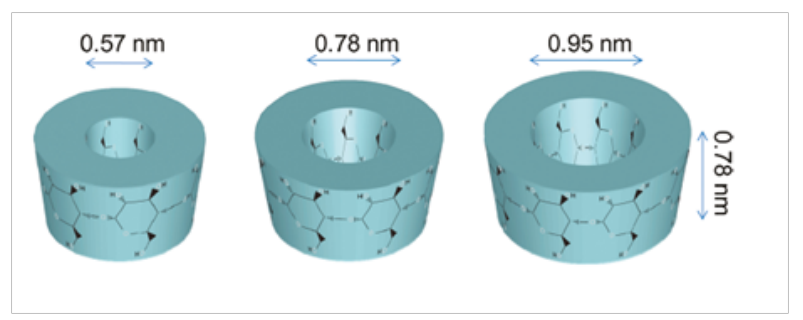

Figure 5 Schematic representation of approximate dimensions of $\alpha-C D$, $\beta-C D$, and $\gamma-C D$.

So our idea to incorporate a cyclodextrine for improvement of vectoraziation of tripeptid in vivo and to insert a large disturbing group between the b-sheet of $\mathrm{A} \beta$ agragation which will imply the rupture of the hydrogen bonds. In addition, the intra-inclusion study of chain Try-Val-Val or inclusion of (A $\beta-42)$ inside the cavity of $C D$ can improve the interaction and blocked the Amyloid Fibrillogenesis.

Tripeptid Try-Val-Val 5 was reacted either with thionyl chloride in the presence of TEA to yield, an acyl chloride that was reacted with aziridine 4 to give breakers $\mathrm{A}$, or coupled in the presence of dicyclohexylcarbodiimide (DCC) as coupling agent with $\mathrm{CD}$ at room temperature, giving the breakers B in medium yield (50-65\%) (Figure $6)$.

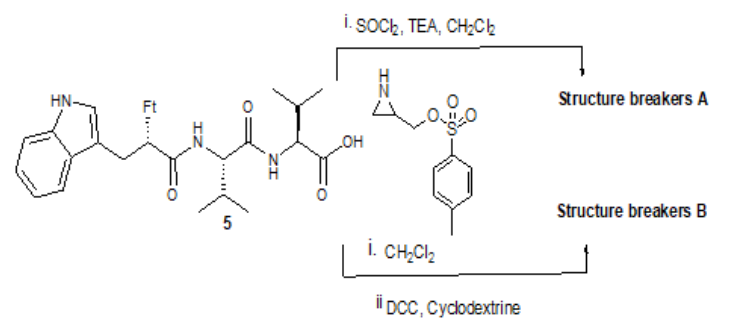

Figure 6 Coupling of aziridines 4 and CD with trypeptid 5.

\section{Primary result of study of interaction of breakers $A$ with A $\beta 42$}

The study by MOE docking showed that structure of brekears A with only aziridine moiety group was the best interaction than B with A 342 (Figure 7). Only biological evaluation in vivo can give wish are the best inhibitors (Figure 8).

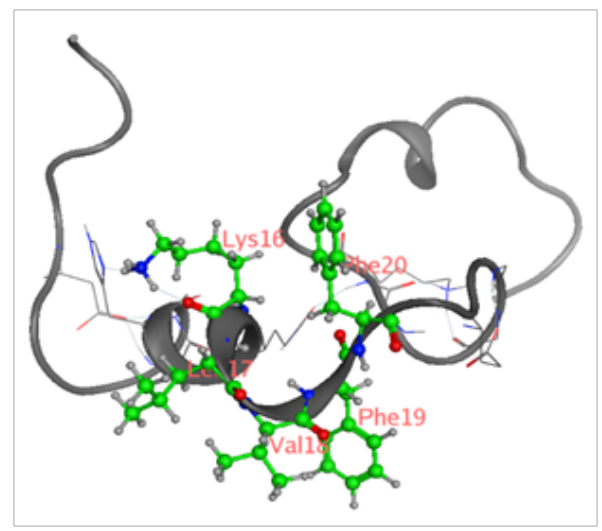

Figure 7 Structure of amyloide A $\beta 42$ with sequence KVLFF (16-17-18-19-20).

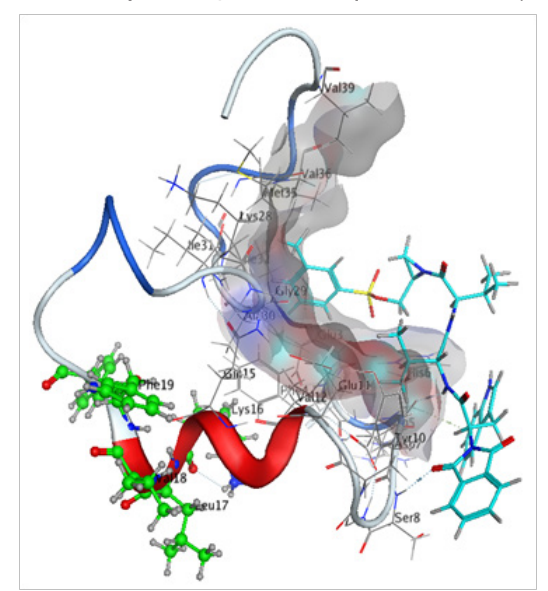

Figure 8 Best interaction of beta sheet breakers with aziridine as disrupting group with amyloide $\mathrm{A} \beta 42$. 


\section{Conclusions}

To conclude we can say that eradicating Alzheimer's disease in a radical way, we are not yet there but the fact to look into this problem by studying the issue of beta amyloid $(A \beta-42)$ remains a fairly studious approach. We developed two inhibitors A and B with aziridine or $\mathrm{CD}$ as disrupting group to be able to stop the fibrillar aggregation, a way still remains to be done to really develop them. in order to ensure their effectiveness, it is necessary to confirm their biological activity. At least in terms of synthesis, the method followed is simple; conventional peptide couplings, which can be improved.

\section{Acknowledgments}

The authors are grateful to Ministry of Higher Education and Scientific Research (Algeria) for the financial support of this work.

\section{Conflicts of interest}

The author declares that there are no conflicts of interest.

\section{References}

1. Aileen Funke1 S, Willbold D. Peptides for Therapy and Diagnosis of Alzheimer's Disease. Current Pharmaceutical Design. 2012;18:755767.

2. Alzheimer A. About a strange disease of the cerebral cortex. All $Z$ psychait. 1907;64:146-148.

3. Lin LX, Bo XY, Tan YZ, et al. Feasibility of $b$-Sheet Breaker Peptide -H102 Treatment for Alzheimer's Disease Based on b -Amyloid Hypothesis. Plosone. 2004.

4. Gorevic P, Castano E, Sarma R, et al. Ten to fourteen residue peptides of Alzheimer's disease protein are sufficient for amyloid fibril formation and its characteristic Xray diffraction pattern. Biochem Biophys Res Commun. 1987;147:854-862.

5. Pike CJ, Overman MJ, Cotman CW. Amino - terminal deletions enhance aggregation of $\beta$-amyloid peptides in vitro. $J$ Biol Chem. 1995;270:23895-23898.

6. Tjernberg LO, Näslund J, Lindqvist F, et al. Arrest of -Amyloid Fibril Formation by a Pentapeptide Ligand. J Biol Chem. 1996;271:85458548 .

7. Tjernberg LO, Lilliehöök C, Callaway DJE, et al. Controlling Amyloid $\beta$-Peptide Fibril Formation with Protease-stable Ligands. J Biol Chem. 1999;272:12601-12605.

8. Tjernberg LO, Callaway DJE, Tjernberg A, et al. A molecular model of Alzheimer amyloid $\beta$-peptide fibril formation. $J$ Biol Chem. 1999;274:12619-12625.

9. Soto C, Sigurdsson EM, Morelli L, et al. $\beta$-sheet breaker peptides inhibit fibrillogenesis in a rat brain model of amyloidosis: Implications for Alzheimer's therapy. Nat Med. 1998;4:822-826.

10. Dufour E. Inhibitors and molecular models of beta and tau amyloid fibers involved in Alzheimer's disease: design. Synthesis and characterization. 2006.

11. Bett CK, Ngunjiri JN, Serem WK, et al. Effects of Peptides Derived from Terminal Modifications of the $\mathrm{A} \beta$ Central Hydrophobic Core on $\mathrm{A} \beta$ Fibrillization. ACS Chem Neurosci. 2010;1:608-626.

12. Hamada Y, Miyamoto N, Kiso Y, et al. Novel $\beta$-amyloid aggregation inhibitors possessing a turn mimic. Bioorganic \& Medicinal Chemistry Letters. 2015;25:1572-1576.

13. Bartolini M, Andrisano V. Strategies for the Inhibition of Protein Aggregation in Human Diseases. Chem Bio Chem. 2010;11:1018-1035.
14. DeToma AS, Salamekh S, Ramamoorthy A, et al. Misfolded Proteins in Alzheimer's Disease and Type II Diabetes. Chem Soc Rev. 2012;41:60 -621 .

15. Convertino M, Pellarin R, Catto M, et al. 9,10 -Anthraquinone hinders beta - aggregation: how does a small molecule interfere with Abeta peptide amyloid fibrillation?" Protein Sci. 2009;18:792-800.

16. Guzior N, Bajda M, Rakoczy J, et al. Isoindoline -1,3-dione derivatives targeting cholinesterases: design, synthesis and biological evaluation of potential anti -Alzheimer's agents. Bioorganic Med Chem. 2015;23:1629-1637.

17. Więckowska A, Więckowski K, Bajda M, et al. Synthesis of new N -benzylpiperidine derivatives as cholinesterase inhibitors with $\beta-$ amyloid anti -aggregation properties and beneficial effects on memory in vivo. Bioorg Med Chem. 2015;23:2445-2457.

18. Guzior N, Bajda M, Skrok M, et al. Development of multifunctional, heterodimeric isoindoline $-1,3$-dione derivatives as cholinesterase and $\beta$-amyloid aggregation inhibitors with neuroprotective properties. Eur J Med Chem. 2015;92:738-749.

19. Panek D, Więckowska A, Wichur T, et al. Design, synthesis and biological evaluation of new phthalimide and saccharin derivatives with alicyclic amines targeting cholinesterases, beta -secretase and amyloid beta aggregation. European Journal of Medicinal Chemistry. 2017; 125:676-695.

20. Lu C, Guo Y, Li J, et al. Design, synthesis, and evaluation of resveratrol derivatives as $\mathrm{A}(42)$ aggregation inhibitors, antioxidants, and neuroprotective agents. Bioorganic \& Medicinal Chemistry Letter. 2012;22:7683-7687.

21. Singh SK. Overview of Alzheimer's Disease and Some Therapeutic Approaches Targeting A $\square$ by Using Several Synthetic and Herbal Compounds. Oxidative Medicine and Cellular Longevity. 2016;22:7361613.

22. Trost BM, Fandrick DR. DYKAT of Vinyl Aziridines: Total Synthesis of (+)-Pseudodistomin D. Org Lett. 2005;7: 823-825.

23. Yadav VK, V Sriramurthy V. Silylmethyl - Substituted Aziridine and Azetidine as Masked 1,3- and 1,4-Dipoles for Formal [3 + 2] and [4+ 2] Cycloaddition Reactions. J Am Chem Soc. 2005;127:16366-16367.

24. Ihata O, Kayaki Y, Ikariya T. Aliphatic Poly(urethane-amine)s Synthesized by Copolymerization of Aziridines and Supercritical Carbon Dioxide. Macromolecules. 2005;38:6429-6434.

25. Kajima Mulengi J, Keniche A, Mezrai A. Unexpected Formation of Azetidines Through Staudinger Reaction of 3-Azido-1,2-diols. Asian Journal of Materials Chemistry. 2016;1:38-44.

26. KenicheA, Drici W, Slimani MZ. 1,3-Dipolarcycloaddition of azomethine ylide from Phtaloylimidophenylalanyl -2 - hydroxymethylaziridine. Mediterr J Chem. 2013;2:583-594.

27. Kajima Mulengi J, Keniche Slimani A. A Bit of Chemistry of aziridines and application. Ed: LAP, 2016. p.80.

28. Keniche A, Bellifa S, Hssaine H, et al. Synthesis of a Novel Class of Phosphonoaziridines as Interesting Antibacterial Agents. Algerian J Nat Products. 2016;4:226-232.

29. Keniche A, Mezrai A, Kajima Mulengi J. Novel class of phosphonoaziridines as antibacterial agents. The Open Conference Proceedings Journal Dubai. 2011;2:28-36.

30. Baba Ahmed FZ, Bouanane S, Merzouk SA, et al. 2-hydroxymethyl1-(Nphtaloyltriptophyl) aziridine stimulates in vitro human lymphocyte proliferation and interleukin secretion. Pathol Biol. 2008;56:137-142.

31. Baba Ahmed FZ, Merzouk H, Bouanane S, et al. Synthesis and Evaluation of Biological Activity of Novel Sugar-Derived Aziridines. Ann Toxicol Anal. 2010. 
32. Kicuntod J, Sangpheak K, Mueller M, et al. Theoretical and Experimental Studies on Inclusion Complexes of Pinostrobin and $\beta$-Cyclodextrins. Sci Pharm. 2018; 30:86-90.

33. Davis ME, Brewster ME. Cyclodextrin - based pharmaceutics: past, present and future. Nature Rev Drug Discov. 2004';3:1023-1035.

34. Szejtli J. Introduction and General Overview of Cyclodextrin Chemistry. Chem Rev. 1988;98:1743-1754.

35. M. Del Valle EM. Cyclodextrins and their Uses: A Review. Process Biochem. 2004;39:1033-1046.

36. Hedges A. Industrial Applications of Cyclodextrins. Chem Rev. 1998;98:2035-2044.

37. Singh M, Sharma R, Banerjee U. Biotechnological applications of cyclodextrins. Biotechnol Adv. 2003;20:341-359.

38. Szejtli J. Cyclodextrins in the textile industry. Starch/Staerke. 2003;55:191-196.
39. Szente L, Szejtli J. Cyclodextrins as food ingredients. Trends Food Sci Technol. 2004;15:137-142.

40. Buschmann HJ, Knittel D, Schollmeyer E. New textile applications of cyclodextrins. J Incl Phenom Macrocycl Chem. 2001;40:169-172.

41. Marcolino VA, Zanin GM, Durrant LR, et al. Interaction of curcumin and bixin with $\beta$-cyclodextrin: complexation methods, stability, and applications in food. Journal of Agricultural and Food Chemistry. 2011;59:3348-3357.

42. Kant A, Linforth RST, Hort J, et al. Effect of beta cyclodextrin on aroma release and flavor perception. J Agric Food Chem. 2004;52:2028-2035.

43. Rekharsky MV, Inoue Y. Complexation Thermodynamics of Cyclodextrins. Chem Rev. 1998;98:1875-1918.

44. Connors KA. The Stability of Cyclodextrin Complexes in Solution. Chem Rev. 1997;97:1325-1358. 